
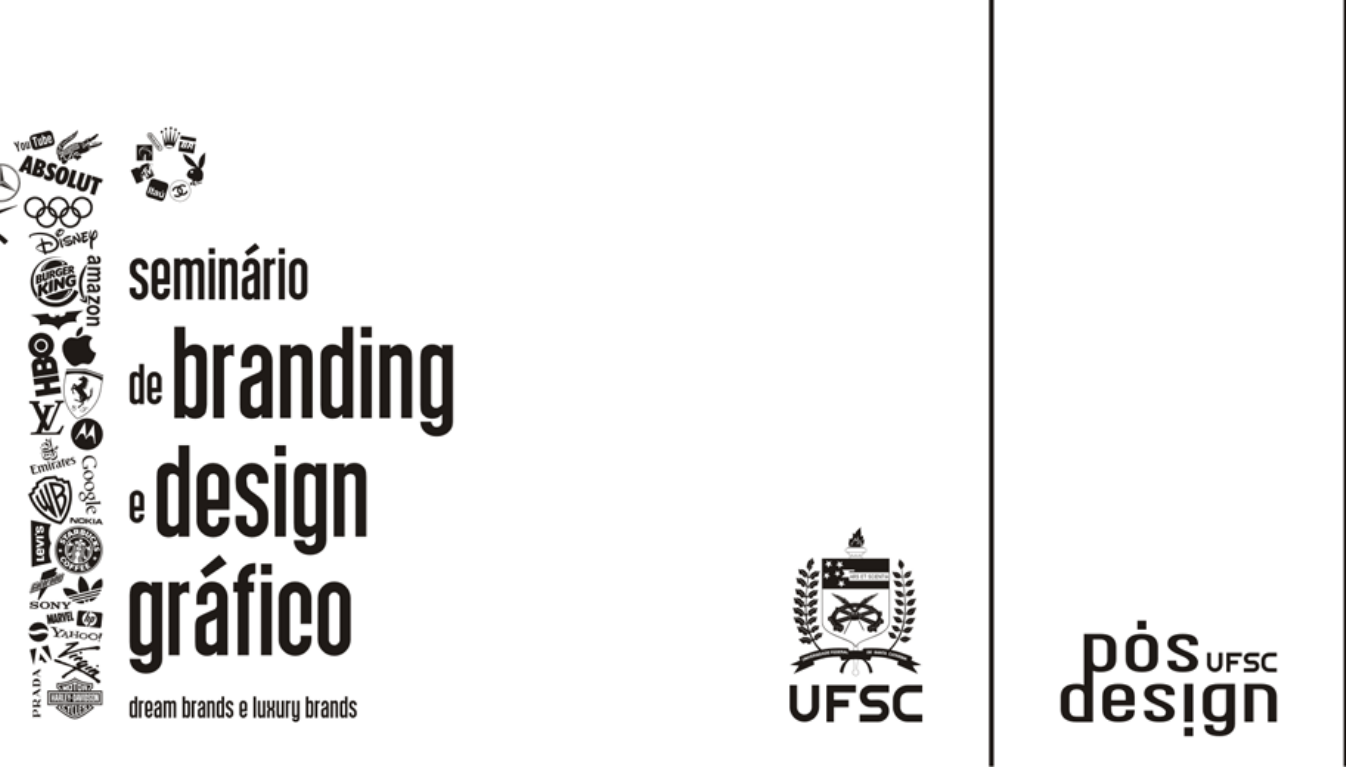

LOGO

\title{
Luxury brand e design gráfico - Dior: um estudo de caso
}

Luxury brand and graphic design - Dior: a case study

POLO, Claudia; Mestranda do programa de Pós-Graduação em Design e Expressão Gráfica UFSC

claudiapolobr@hotmail.com

\section{Resumo}

Este estudo de caso tem como objetivo apresentar a relação entre a marca Christian Dior e o design gráfico. Para que seja realizado esse estudo é necessário apresentar um breve histórico da marca, sua posição atual no mercado e a importância de sua identidade e aparência em sua expressão e comunicação.

Palavras-chave: design gráfico, marca, luxury brand

\section{Abstract}

This case study has as objective to present the relation enters the brand Christian Dior and the graphic design. So for this study is necessary to present a historical of the brand, its current position in the market and the importance of its identity and appearance in its expression and communication.

Keywords: graphic design, brand, luxury brand 


\section{Introdução}

As marcas que atuam no segmento de luxo possuem como característica principal oferecer muito além de produtos de qualidade. Para se destacar nesse setor é necessário disponibilizar aos consumidores um completo estilo de vida, traduzido por todo o contexto que acompanha o relacionamento entre o produto e seu comprador, durante um processo completo de estímulo, compra e utilização. A característica inerente a esse segmento implica, obrigatoriamente, na sintonia entre a identidade da marca e as percepções que os consumidores possuem dela - sua "imagem".

Para a construção e manutenção dessa sintonia é necessário que a empresa desenvolva estratégias. O design é um dos aliados nesse sentindo, reunindo, além da possibilidade de criação de um diferencial, a atribuição de valores que ultrapassam a mera percepção dos benefícios funcionais do produto, gerenciando um conjunto de qualidades tangíveis e intangíveis.

Nesse estudo de caso, apresenta-se a marca Christian Dior, fundada em 1947, que concentra ações ao longo de sua existência para manter uma personalidade, características próprias, estilo e valores.

A percepção da marca envolve aspectos objetivos e subjetivos em sua relação com os consumidores. A marca se expressa de várias maneiras sendo que na maioria delas visualmente; e é através dessa comunicação que se criam as representações e associações na imaginação do cliente. $\mathrm{O}$ trabalho de design gráfico é realizado no sentido de estabelecer um conceito adequado e uma identidade para a marca, o que justifica o estudo dessa relação entre a marca e o design gráfico. Sendo assim, qual a participação do design gráfico na marca Christian Dior?

Para responder a essa questão é necessário apresentar um histórico da marca, como ela se relaciona com o mercado e quais são a importância e a função de sua aparência no processo de comunicação.

\section{DIOR e sua História}

Em 1947, Christian Dior, francês de Granville (cidade portuária da Mancha) apresentou seu primeiro desfile. Sua coleção foi batizada de "New Look" pela redatora da revista "Harper's Bazaar" americana, Carmel Snow. O "New Look" era, basicamente, composto por saias amplas quase até os tornozelos e cinturas bem marcadas. A proposta da coleção era vestir a mulher de maneira feminina e elegante (POCHNA, 2000).

O modelo que se tornou o símbolo do "New Look" foi o "tailleur Bar", um casaquinho de seda bege acinturado e ampla saia preta plissada quase na altura dos tornozelos. Luvas, sapatos de saltos altos e chapéu completavam o figurino. Segundo Pochna (2000), com essa imagem de glamour, estava definido o padrão dos anos 50.

Conforme Baudot (2000, p.157), a marca Dior assegurou sozinha metade das exportações para os Estados Unidos, durante os anos 50. Já em 1949, Christian Dior tinha uma casa de prê-àporter que vendia artigos de luxo em Nova York e o perfume "Miss Dior" - lançado em 1947 e fabricado até hoje. A partir de 1950, surgiu um outro tipo de sociedade, incumbida do comércio por atacado e da difusão dos acessórios com a marca Dior.

Para Pochna (2000), Christian Dior foi "o primeiro estilista a fundar uma indústria do luxo, Dior transformou sua maison em sinônimo de bom gosto e elegância." Em dez anos de carreira, foi o estilista mais cultuado e admirado no mundo da moda, suas criações foram sucesso e seu nome associado à sofisticação e ao refinamento. 
Christian Dior morreu, de ataque cardíaco, em 1957, na estação termal Toscana de Montecatini, na Itália, deixando vinte e oito ateliês e mais de mil empregados. O escolhido para ser seu sucessor foi o estilista iniciante Yves Saint-Laurent, que tinha apenas vinte e um anos. Em 1960, Saint-Laurent foi convocado para servir na guerra da Argélia e em 1962, quando voltou a Paris, abriu sua própria empresa. Em seu lugar, foi contratado o estilista francês, Marc Bohan. Em 1989, foi contratado o italiano Gianfranco Ferré e seu estilo de linhas arquitetônicas e corte seco seguiu até 1997, ano em que assumiu o inglês John Galliano, atual estilista e responsável pelo revigoramento da marca ${ }^{1}$.

Desde 1984, a marca Dior é controlada pelo grupo $\mathrm{LVMH}^{2}$ (Môet-Henessy Louis Vuitton), primeira empresa mundial do comércio de luxo, do engenheiro francês Bernard Arnault. A marca, que começou a se estender sob o próprio Christian Dior com o perfume "Miss Dior", foi ampliada e atualmente cobre doze categorias, entre elas, prêt-a-porter (roupas femininas e masculinas), marroquinerie (bolsas, sapatos, cintos e carteiras), acessoires (maillots, foulards, bonés, bijuterias e guarda-chuvas), art de la table (artigos para casa), óculos, perfumes e cosméticos, haute joaillerie (jóias) e baby Dior (linha infantil).

Em todas as categorias e em grande parte dos produtos da marca observa-se o destaque do nome, do logotipo e/ou das inicias compostas pelas letras "C" e "D".

\section{Nome, Logo e Logomania}

Para Chevalier e Mazzallovo (2007, p.25) o nome de uma marca ou o seu logotipo constitui uma parte visível importante de uma realidade complexa. O nome e o logotipo proporcionam a mediação entre os valores essenciais de uma empresa - sua identidade - e as percepções que os consumidores possuem dela - sua "imagem".

A marca se afirma através de alguns sinais. Os sinais são de diversas ordens, muitas vezes inter-relacionados. Para Aaker (1998, p.10) "a marca é identificada pelo nome e, frequentemente, por um símbolo e também por um slogan". Para se expressar, a marca usa elementos diferentes e complementares, a começar pelo próprio nome. O nome do fundador da marca Christian Dior consolidou um valor vinculado à personalidade de seu criador, originando uma identidade duradoura. A memória de seu criador, o carisma e a reputação são fatores relevantes. Christian Dior havia consolidado um valor, um "espírito de marca" mais do que a qualidade dos serviços ou produtos (CHEVALIER; MAZALLOVO, 2007).

Percebe-se, neste caso, um fenômeno interessante a ser observado que é o desaparecimento progressivo do prenome "Christian". Até 1995, os produtos e a propaganda sempre levavam a assinatura completa (Fig. 1). Durante um longo tempo foi mostrado de maneira simplificada na propaganda, mas inteiro na parte inferior do anúncio e embalagens. Hoje, é cada vez mais comum a marca aparecer só com o sobrenome "Dior" (Fig. 1) nos produtos e anúncios (CHEVALIER; MAZALLOVO, 2007).

\footnotetext{
1 Extraído de http://www.dior.com. Acesso em 05 de maio de 2008.

${ }^{2}$ O grupo LVMH está entre os líderes do mercado de luxo mundial e engloba diversas empresas e marcas como Louis Vuitton e Moët \& Chandon e Henessy.
} 


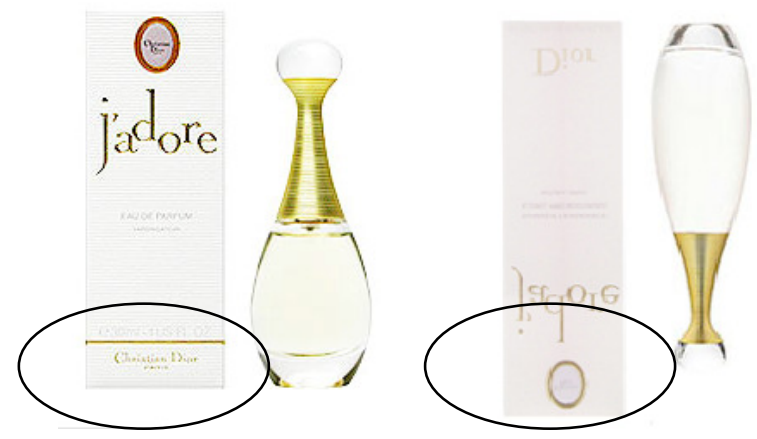

Figura 1: Produtos com o nome completo e só com o sobrenome Dior.

Fonte: da autora (a partir de www.dior.com)

Assim como o nome, os símbolos gráficos que representam as empresas precisam estar fortemente ligados à identidade da marca, ao seu significado. "[...] o símbolo pode ser a característica distintiva da marca, o elemento central do capital marca" (AAKER, 1998, p.208). Para Chevalier e Mazallovo (2007), disseminar o logo em todos os registros da comunicação (Fig. 2) constitui uma maneira simples para universalizar a representação da marca. Eles são visíveis nos produtos até o ponto em que se tornam, principalmente no universo da moda, sinais concretos de um valor agregado.
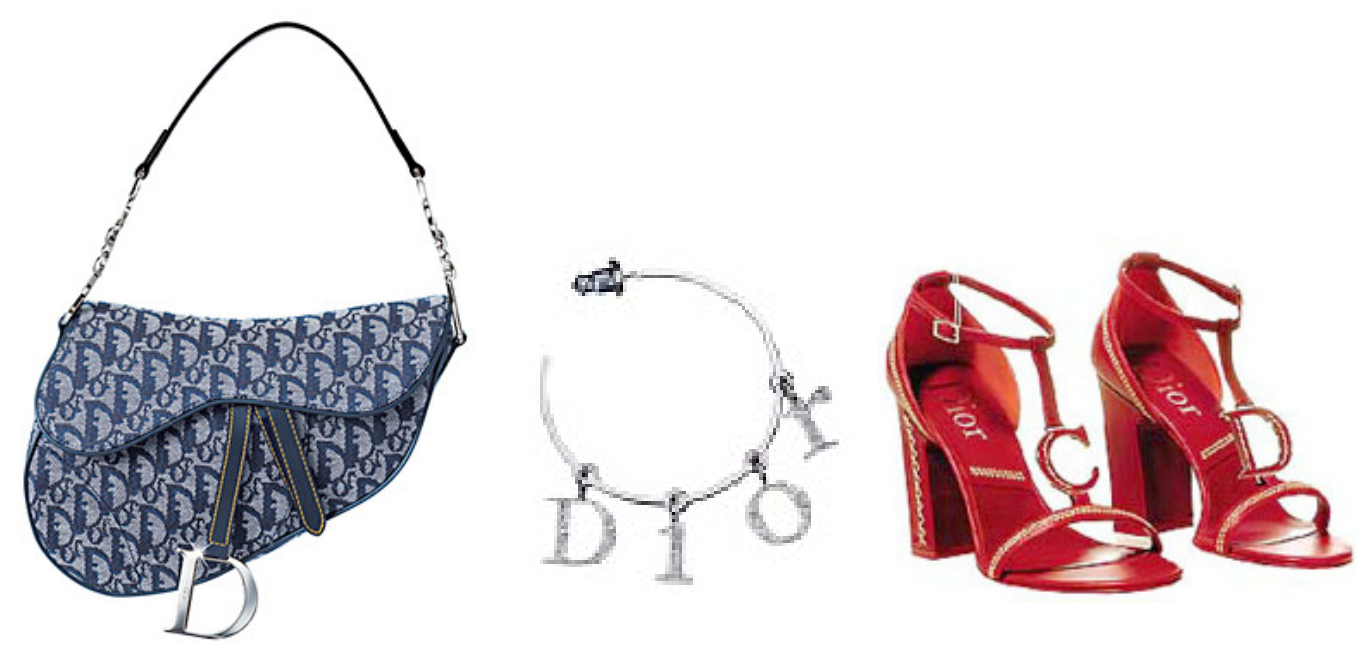

Figura 2: Produtos com o logotipo da marca

Fonte: da autora (a partir de www.dior.com)

\section{Marca e Identidade de Marca}

Segundo Aaker (2007, p.49), "uma marca forte deve ter uma identidade de marca clara e valiosa." O designer pode contribuir através de um programa de design bem-sucedido que "permite ordenar a forma pela qual se faz a comunicação visual da instituição ou empresa e, por meio dele, podemos dirigir, com um nível bastante razoável de segurança, o modo pelo qual o entendimento das imagens se processa" (STRUNCK, 1989, p.10). Gobé (2002, p.212) concorda 
ao afirmar que "se a identidade de uma marca não for bem definida, pode-se obter visibilidade, mas nenhuma personalidade."

O design pode ajudar a criar e manter a imagem da marca, seus valores e sentimentos que ultrapasam a mera percepção dos benefícios funcionais dos produtos. Gomez (2007) afirma que "as peças gráficas são fundamentais na apresentação da marca, explorando aspectos simbólicos e, assim, promovendo a lealdade do consumidor, criando vínculo emocional para vender o valor da marca."

Gobé (2002, p.157) acredita que "o design seja a expressão mais potente de uma marca e que trazer à vida idéias poderosas, seja a melhor maneira de criar um elo duradouro entre um fabricante ou um varejista e o consumidor". Roux (2005, p.136) concorda ao afirmar que "a imagem de uma marca corresponde, então, ao conjunto das associações estocadas na memória do consumidor". Como um sinal perceptível, a marca leva o consumidor a reconhecer algo simbólico além de sua aparência, sobrepondo aos produtos uma outra marca ideal, afetiva e conceitual. Essa última resulta do conjunto de percepções do consumidor, que é decorrente do seu convívio com as estratégias de divulgação da marca e também do uso de seus produtos e serviços (SOUSA, 2001, p.34).

\section{Considerações Finais}

Observa-se que a Dior imprime sua MARCA VISUAL de maneira coerente e integral em seus produtos e em sua comunicação das seguintes maneiras :

\section{Design nos produtos (Fig.3)}

O design nos produtos proporciona uma capacidade identificativa e diferenciadora, um maior impacto visual e maior valor informativo pela aplicação do logo, pelas formas, por todo o conjunto e sofisticação.

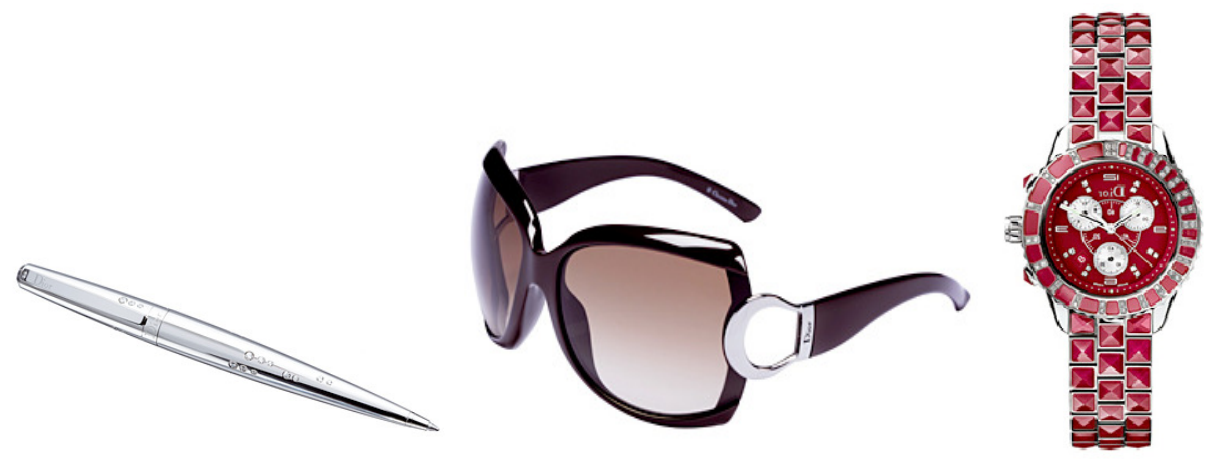

Figura 3: Design nos produtos.

Fonte: da autora (a partir de www.dior.com).

\section{Design na comunicação da marca (Fig.4)}

O design na comunicação evidencia os valores da empresa, diferencia a empresa dos concorrentes e aumenta a eficácia dos meios de comunicação. 

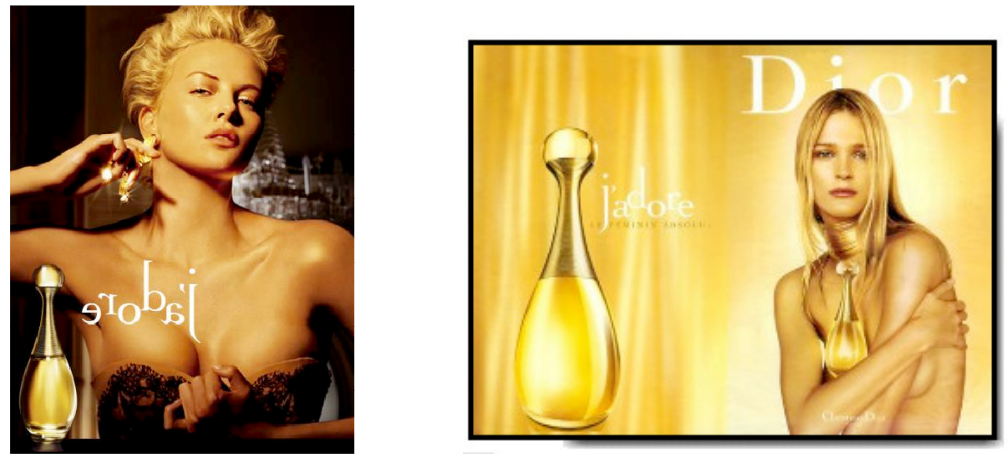

Figura 4: Design na comunicação da marca.

Fonte: da autora (a partir de www.dior.com)

O design gráfico participa de todo o processo de expressão da marca, fazendo com que a mesma deixe de representar apenas o produtor ou o vendedor dos produtos e passe a representar efetivamente os valores e conceitos da marca.

Christian Dior pode ser considerada uma marca com identidade coerente, por manter uma personalidade, considerando que desde seu lançamento, seu fundador imprimiu os conceitos de luxo, elegância e feminilidade nos produtos e na comunicação da marca.

A Empresa, com essa identidade de marca bem definida e comunicada de forma coesa e harmoniosa, conseguiu criar um elo duradouro com seus consumidores (AAKER, 2007; GOBÉ, 2002; GOMEZ, 2007). Foi capaz de se renovar continuamente, ao longo do tempo, sem contradizer sua essência. Apesar de Christian Dior ter permanecido por apenas dez anos à frente da marca, seus valores foram mantidos através do gerenciamento de fatores intangíveis, ligados à personalidade da marca que está permeada pela personalidade do seu criador original.

\section{Referências}

AAKER, David A. Marcas: Brand Equity - gerenciando o valor da marca. São Paulo: Negócio Editora, 1998.

AAKER, David A; JOACHIMSTHALER, Erich. Como Construir Marcas Líderes. Porto Alegre: Bookman, 2007.

BAUDOT, François. Moda do Século. São Paulo: Cosac \& Naify Edições, 2000.

CHEVAliER, Michel; MAZZALOVO, Gérald. Pró Logo. Marcas como Fator de Progresso. Tradução: Roberto Galman. São Paulo: Panda Books, 2007.

GOBÉ, Marc. A emoção das marcas: conectando marcas às pessoas. Rio de Janeiro: Campus, 2002. 
GOMEZ, L. S. R.; SILVA, G.G. Visual Communication Branding. In: Design \& cc: SOS! Design and Commercial Comunications: Seek Optimal Synergies: Lisboa, 2007.

MÔET-HENESSY LOUIS VUITTON. Disponível em <http://www.lvhm.com>. Acesso em 05 d maio de 2008.

LIPOVETSKY, Gilles; ROUX, Elyette. O Luxo Eterno. São Paulo: Companhia das Letras, 2005.

POCHNA, Marie-France. Universo da Moda: Dior. São Paulo: Cosac Naify, 2000.

SOUSA, Richard Perassi Luiz. A Visualidade das Marcas Institucionais e Comerciais como

Campo de Significação. Tese (Doutorado em Comunicação e Semiótica) - Pontifícia Universidade Católica de São Paulo, São Paulo, 2001.

STRUNCK, Gilberto. Como Criar Identidades Visuais para Marcas de Sucesso. São Paulo: Panda Books, 1998. 